$\curvearrowright$

PERSONNEL ASSESSMENT

A ND DECISION S
Personnel Assessment and

Decisions

\section{Volume 7 \\ Issue 1 Special Issue: Understanding Effects of \\ Impression Management on Assessment \\ Outcomes}

\title{
Unintended Consequences of Interview Faking: Impact on Perceived Fit and Affective Outcomes
}

\author{
Brooke D. Charbonneau \\ Department of Psychology, University of Guelph \\ Deborah M. Powell \\ Department of Psychology, University of Guelph \\ Jeffrey R. Spence \\ Department of Psychology, University of Guelph \\ Sean T. Lyons

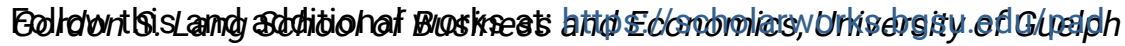 \\ Part of the Human Resources Management Commons, Industrial and Organizational Psychology \\ Commons, and the Other Psychology Commons \\ How does access to this work benefit you? Let us know!
}

\section{Recommended Citation}

Charbonneau, Brooke D.; Powell, Deborah M.; Spence, Jeffrey R.; and Lyons, Sean T. (2021) "Unintended Consequences of Interview Faking: Impact on Perceived Fit and Affective Outcomes," Personnel Assessment and Decisions: Number 7 : Iss. 1 , Article 6.

DOI: https://doi.org/10.25035/pad.2021.01.006

Available at: https://scholarworks.bgsu.edu/pad/vol7/iss1/6

\section{(c) (i)}

This work is licensed under a Creative Commons Attribution 4.0 International License.

This Main Article is brought to you for free and open access by the Journals at ScholarWorks@BGSU. It has been accepted for inclusion in Personnel Assessment and Decisions by an authorized editor of ScholarWorks@BGSU. 


\title{
Unintended Consequences of INTERVIEW FAKING: IMPACT ON Perceived Fit and Affective OuTCOMES
}

\author{
Brooke D. Charbonneau ${ }^{1}$, Deborah M. Powell ${ }^{1}$, Jeffrey R. \\ Spence ${ }^{1}$, and Sean T. Lyons ${ }^{2}$
}

1. Department of Psychology, University of Guelph

2. Gordon S. Lang School of Business and Economics, University of Guelph

ABSTRACT

\begin{abstract}
Drawing on signalling theory, we propose that use of deceptive impression management (IM) in the employment interview could produce false signals, and individuals hired based on such signals may incur consequences once they are on the job-such as poor perceived fit. We surveyed job applicants who recently interviewed and received a job to investigate the relationship between use of deceptive IM in the interview and subsequent perceived personjob and person-organization fit, stress, well-being, and employee engagement. In a twophase study, 206 job applicants self-reported their use of deceptive IM in their interviews at Time 1, and their perceived person-job and person-organization fit, job stress, affective well-being, and employee engagement at Time 2. Deceptive IM had a negative relationship with perceived person-job and person-organization fit. As well, perceived fit accounted for the relationship between deceptive IM and well-being, employee engagement, and job stress. The findings indicate that using deceptive IM in the interview may come at a cost to employees.
\end{abstract}

deceptive impression management, faking, person-job fit, personorganization fit, employment interview

Personnel selection involves a back and forth exchange of information between job candidates and hiring organizations; the main goal of this information exchange is to maximize the "fit" between candidate abilities and job demands (Saks \& Ashforth, 1997). If information about the organization's needs and the candidate's skills are accurately exchanged, this should lead to good fit. In a well-functioning information exchange, an organization would make it clear in the job ad what the required skills are, and the job candidate would accurately signal their skills during the selection process. However, in selection situations, neither the employer nor the job candidate can communicate nor receive information perfectly. An employer typically cannot directly and accurately observe a potential employee's skills prior to hiring nor can an employee communicate their exact level of each skill. Instead, organizations collect information about the applicants, which includes previous education, experience, and the image the individual presents in an indirect and time-limited manner (e.g., through resumes and interview responses), and use this information to assess fit (Bangerter et al., 2012). The information exchange framework assumes that organizations and applicants are exchanging information in good faith. But what happens if the information provided by an applicant is intentionally misleading? What if an interviewee omits important information (e.g., they do not mention that they were fired from their last job for always being late), or they exaggerate the truth to appear like a better candidate for the job (e.g., by describing time management skills that their friend uses)? This may result in a situation where an organization perceives there is good fit when there is not. These strategies of exaggerating or omitting information during the interview are known as deceptive impression management (IM) or interview faking (Levashina \& Campion, 2007). Levashina and Campion reported that over $90 \%$ of the undergraduate job applicants in their studies engaged in some form of deceptive impression management during their past employment interviews. Despite the common use of deceptive IM, little is known about the consequences for interviewees and organizations who use this technique, if they are eventually hired.

Corresponding author:

Deborah M. Powell

Email: dpowell@uoguelph.ca 
In the current study, we explore whether there may be hidden consequences of faking during the interview for applicants. Specifically we investigate whether faking during the interview is related to increased stress and decreased well-being and engagement for successful applicants, once on the job, and whether these effects are mediated by person-job and person-organization fit. This study contributes to the employee selection literature concerning personjob and person-organization fit by proposing a mechanism by which poor fit may result, even despite the employer's explicit efforts to ensure fit. By examining the post-employment consequences of successful deceptive IM, this study focuses on the deleterious effects of deceptive IM practices for the employee, despite the benefits it might provide in attaining employment.

\section{Deceptive Impression Management}

Deceptive IM in the interview was first defined, as a construct separate from IM more generally, by Levashina and Campion (2006) in their model of faking likelihood. They argued that deceptive IM was something distinct from broad impression management, and they subsequently developed a measure of deceptive IM (Levashina \& Campion, 2007). Their measure includes four dimensions of deceptive IM: slight image creation, extensive image creation, image protection, and deceptive ingratiation. Although distinct techniques, they are highly correlated and are frequently combined into an overall deception IM scale (e.g., intercorrelations ranged from .70-.86 in Bourdage et al., 2018). Building on this distinction of deceptive IM from IM more generally, Levashina and Campion also argued that honest IM should be measured separately from deceptive IM, in order to distinguish the antecedents and consequences of honest versus deceptive forms of IM. Bourdage et al. (2018) subsequently developed a measure of honest IM, which includes subscales of honest self-promotion, honest ingratiation, and honest defensive IM. Although correlated with each other, honest and deceptive IM do appear to have different antecedents and outcomes.

According to their model of faking likelihood, Levashina and Campion argue that the most proximal antecedents to faking are applicants' capacity, willingness, and opportunity to fake. Other models of applicant faking behavior have also been proposed (e.g., Marcus, 2009; McFarland \& Ryan, 2006). In general, these models have tended to focus on the antecedents to faking, and few models have considered the outcomes of interview faking. McFarland and Ryan (2006) suggested that faking may influence applicants' scores. However, in a recent review, Melchers et al. (2020) noted that the effectiveness of deceptive IM is unclear. In their review, they found that the correlations between self-reported deceptive IM and interview outcomes (e.g., interview scores) ranged from small and negative to near zero, to moderate and positive. In this study, we will investigate consequences of using deceptive IM, from the perspective of successful job candidates.

\section{Signalling Theory of Personnel Selection}

Job candidates and organizations engage in an information exchange during the selection process, a process described by Bangerter et al. (2012) using signalling theory. Signalling theory, derived from evolutionary biology, proposes that in situations where individuals seek to enter into an exchange where perfect information exchange is impossible, both parties engage in signalling behavior to share information indirectly (Spence, 1973). In the selection context, performance on selection tools can be used as a signal of candidates' qualifications. For example, a university degree could be a signal used to infer a certain level of knowledge gained during a degree program or the effort put into obtaining the degree. Signalling theory suggests that the potential for imperfect information exchange is greatest when the two parties have imperfectly aligned motives. Personnel selection is such a situation, because organizations' goals of obtaining accurate information about applicants are imperfectly aligned with applicants' goals of distinguishing themselves as the most attractive candidate. Signalling theory focuses primarily on situations where the signaller deliberately conveys positive (if not entirely true) signals about their underlying traits (Connelly et al., 2011). These situations can arise during the selection context when applicants may decide to engage in deceptive impression management because they have the goal of obtaining a job. For example, candidates might omit that it took them 6 years to obtain a 4-year degree due to time management challenges, and the organization may not take the time to confirm dates of registration.

Applying signalling theory to personnel selection, Bangerter et al. (2012) argued that faking during the selection process comes with risk, such as being caught and eliminated from the selection process. Although getting caught faking and being eliminated from contention is a clear risk, we propose that faking signals in the selection context may carry additional, hidden risks even if they are not detected. For example, applicants who successfully convince an organization they have a degree when in fact they do not are putting themselves at risk of getting a job for which they are not qualified. Being underqualified for a job will likely come with psychological costs. Using a milder example, individuals could fake a signal in an interview by stating that they enjoy working in a very fast-paced environment, when in fact they prefer a slower, more methodical pace of work. If the organization is fast paced and applicants get hired, they must now bear the cost of being in an environment they do not enjoy. This potentially hidden cost to faking would be a poor fit between the applicants' skills or values and the organization or job position.

Signalling theory argues that personnel selection is primarily concerned with identifying signals of applicants' fit with the organization (Bangerter et al., 2012). Identifying accurate signals of applicants' abilities corresponds to an assessment of person-job (PJ) fit. That is, do the abilities of the applicant correspond to the abilities needed by the orga- 
nization to do the particular job. Identifying signals of applicant commitment corresponds to assessment of personorganization (PO) fit, or whether the values of the applicant correspond to the culture of the organization (Bangerter et al., 2012). Whereas the organization is trying to identify honest signals of ability and commitment, applicants may send dishonest signals by engaging in deceptive IM. Indeed, applicants' use of IM in interviews has been found to influence interviewers' perceptions of PJ and PO fit (see Bourdage et al., 2018; Kristof-Brown et al., 2002). However, there is less work on deceptive IM in this area. Because sending dishonest signals will disrupt the ability of the organization to accurately assess person-job and personorganization fit, we hypothesize that faking in the interview will be negatively associated with both types of fit once applicants are on the job.

Hypothesis 1: Applicants' use of deceptive IM (during the interview) will be negatively related to their perceived (a) person-job and (b) person-organization fit, once on the job.

We did not have specific hypotheses about the relations between honest IM and person-job and person-organization fit; however, we included a measure of honest IM to test whether the effects of honest IM and deceptive IM might be different with respect to fit. ${ }^{1}$

\section{“Costly" Work Outcomes of Deceptive IM}

Both person-job and person-organization fit are associated with other important consequences for employees, such as job satisfaction, performance, stress, productivity, and turnover (Rounds \& Tracey, 1990). Edwards and Shipp (2007) categorized these outcomes, which are associated with fit, into three broad categories: job attitudes (e.g., job satisfaction and organizational commitment), performance (task and contextual performance), and mental and physical well-being (e.g., stress). The focus of this study is the effects of person-job and person-organization fit on employee mental well-being. Specifically, we assess whether individuals who have lower perceptions of fit will report more stress, lower affective well-being, and lower employee engagement.

Therefore, the following hypotheses were tested:

Hypothesis 2: Perceptions of person-job fit will be (a) negatively related to work stress, (b) positively related to affective well-being, and (c) positively related to employee engagement.

Hypothesis 3: Perceptions of person-organization fit will be (a) negatively related to work stress, (b) positively related to affective well-being, and (c) positively related to employee engagement.
The overarching purpose of this study is to examine whether there is a hidden psychological cost to job applicants when they misrepresent themselves using deceptive IM in the interview. To do so, we test whether deceptive IM will lead to a lack of perceived fit once the employee is on the job and whether (mis)fit has consequences such as higher stress, lower affective well-being, and lower employee engagement (see Figure 1). Thus, we hypothesized that:

Hypothesis 4: Deceptive IM will be (a) positively related to job stress, (b) negatively related to affective well-being, and (c) negatively related to employee engagement, and these relationships will occur via an indirect effect through person-job fit.

Hypothesis 5: Deceptive IM will be (a) positively related to job stress, (b) negatively related to affective well-being, and (c) negatively related to employee engagement, and these relationships will occur via an indirect effect through person-organization fit.

We preregistered these hypotheses, and the model on which they were based, with the Open Science Framework. ${ }^{2}$ To test these hypotheses, we conducted a two-phase study, tracking applicants through the selection process to their work experience. Self-reports of the use of IM during the interview were collected shortly after the participants completed an interview (and obtained a job). Then, self-reports of fit and the well-being variables were collected after participants had spent almost 2 months on the job.

\section{METHOD}

\section{Participants}

Participants were 206 co-operative education (co-op) students $^{3}$ from two higher educational institutions in Canada. The students were invited to participate in the study through their respective career services office, after they underwent interviews for their work term and accepted a position. The sample was $71 \%$ female; mean age $=20.45$ years. The majority of participants were of white/European descent (69\%); however, participants of Southeast Asian (14\%), South Asian (10\%), Black/African/Caribbean (2\%), Latin American (1\%), Arab (1\%), First Nations/Métis/Inuit $(1 \%)$, or other $(3 \%)$ descents also participated in the study.

\footnotetext{
1 We would like to thank an anonymous reviewer for suggesting that we also analyze honest IM.

2 https://osf.io/3q7x5/?view_only=a501ee4fba114881a56429617b61aca2, https://osf.io/jc8uh/?view_on-

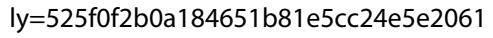

3 Co-operative education is a common form of work-integrated learning in Canada where students complete their degree while alternating between academic terms and paid work terms with various organizations.
} 
FIGURE 1.

Model testing the role of perceived person-job fit on the relationship between deceptive IM and affective outcomes

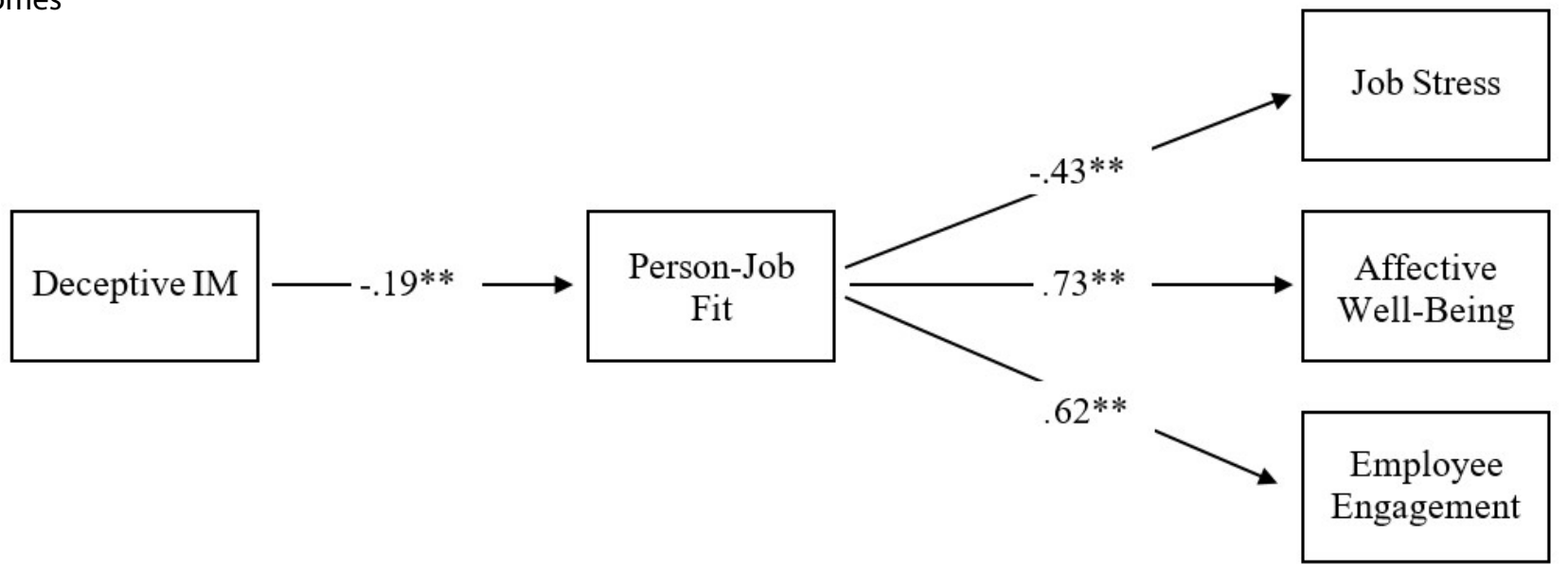

Note. Indirect effect between deceptive IM and job stress was $.08^{* *}$, between deceptive IM and affective well-being was $-.14^{* *}$, and between deceptive IM and employee engagement was $-.12^{* *} .{ }^{*} p<.05,{ }^{* *} p<.01$.

The students were in a variety of different academic programs.

\section{Procedure}

Time 1. Participants were contacted by their Career Services offices shortly after their interviews, after they had accepted a co-op position, but prior to starting the job, and asked to take part in the study. The students were asked to think about the job interview for the position that they accepted while they completed the survey (they may have had other interviews, either successful or unsuccessful). Participants were informed that their responses would be confidential and that their future employer would not be privy to the results of the study. At this time, participants completed a questionnaire (measures described below) and provided their email address to match up their Time 1 and Time 2 survey data.

Time 2. All participants were contacted again after they spent approximately 2 months working at their new job. This 2-month timeframe was chosen as it was the halfway point in the participants' 4-month work terms. Participants were contacted via the same means as the first survey and were asked to fill out a second survey. Participants who completed both Time 1 and Time 2 surveys received a $\$ 5$ Starbucks e-gift card.

\section{Measures-Time $1^{4}$}

Deceptive impression management. Deceptive IM was assessed with the Interview Faking Behavior-Short (IFB-S) scale (Bourdage et al., 2018). These researchers shortened the original Interview Faking Behavior scale created by Levashina and Campion (2007) to create a shorter version. In the IFB-S, participants rate 16 items on a five-point scale $(1=$ strongly disagree; $5=$ strongly agree $)$. Sample items include "I tried to express the same opinions and attitudes as the interviewer" and "I invented some work situations or accomplishments that did not really occur." Deceptive IM had a reliability of $\alpha=.80$ in our sample.

Honest impression management. Honest IM was assessed with the Honest Interview Impression Management-Short (HIIM-S) scale developed by Bourdage et al. (2018). In the HIIM-S, participants rate 12 items on a scale from 1 (strongly disagree) to 5 (strongly agree). Sample items include "I make sure to let the interviewer know about my job credentials" and "I gave reasons why I felt I benefited positively from a negative event I was responsible for." We found a reliability of $\alpha=.62$ in our sample.

Demographic information. Demographic information was collected, including participants' age, gender, ethnicity, year of study, and academic program.

\section{Measures-Time 2}

Perceived person-job fit. Employee perceptions of person-job fit were measured using the 5-item perceived person-job fit scale developed by Saks and Ashforth (1997). Items are rated on a 5 -point scale $(1=$ to a very little extent; 5 = to a very large extent). Sample items include "To what extent do your knowledge, skills, and abilities match the requirements of the job?" and "To what extent is the job a good match for you?" We obtained a reliability of $\alpha=.85$

4 Participants also filled out self-verification striving and interview anxiety scales at Time 1 ; however, these variables were not analyzed in this study. 
for person-job fit.

Perceived person-organization fit. Employee perceptions of person-organization fit were measured using the 5 -item perceived person-organization fit scale developed by Saks and Ashforth (1997). Items are rated on a 5-point scale $(1=$ to a very little extent; 5 = to a very large extent $)$. Sample items include "To what extent are the values of the organization similar to your own values?" and "To what extent does the organization fulfill your needs?" We obtained a reliability of $\alpha=.89$ for this scale.

Job stress. Job stress was measured with the Job Stress Scale developed by Lambert et al. (2006). Participants rated five items that measure an individual's overall level of job stress on a 5 -point scale $(1=$ strongly disagree; $5=$ strongly agree). Sample items include "I am usually under a lot of pressure when I am at work" and "I am usually calm and at ease when I'm working." Job stress had a reliability of $\alpha=$ .86 in our sample.

Affective well-being. Participants' affective well-being was assessed using the Job-Related Affective Well-Being Scale (Van Katwyk et al., 2000). This scale contains 15 items representing positive affect and 15 items representing negative affect, answered on a 5-point rating scale $(1=$ never; $5=$ extremely often or always.) The negative affect items were reversed scored so that high scores indicate high levels of affective well-being. Sample items include "My job made me feel proud" and "My job made me feel frustrated." We found a reliability $\alpha=.95$ on this scale.

Employee engagement. Participants completed Saks' (2006) job engagement scale to assess their employee engagement. This scale has six items, answered on a 5-point scale $(1=$ strongly disagree; $5=$ strongly agree $)$ and measures an individual's overall job engagement. Sample items include "Sometimes I am so into my job that I lose track of time" and "I really 'throw' myself into my job." Our sample had a reliability of $\alpha=.81$ on employee engagement.

Attention checks. Additionally, two attention check questions ("Please answer 'somewhat agree' for this question"), an honesty check question ("I answered the survey questions honestly"), and a researcher trust question ("How confident are you that your responses from this questionnaire will be kept confidential?") were included in both Time 1 and Time 2 questionnaires.

\section{RESULTS}

\section{Data Handling and Cleaning}

469 participants began the Time 1 survey; of these 469 participants, 206 were included in the analysis. Participants who did not correctly answer both attention check questions were not included in the analysis $(n=18)$. Additionally, participants who selected 1 (strongly disagree/extremely unconfident) or 2 (disagree/unconfident) to the honesty check or researcher trust check questions were not included in the analysis $(n=22)$. We screened our data set for careless responding using the longstring test from the careless package in $\mathrm{R}$, and removed three additional participants who provided the same answer to more questions in a row than could reasonably be answered in the same way (13 in a row for Survey 1 and 14 in row for Survey 2). The other 220 participants did not complete either survey $1(n=157)$ or survey $2(n=63){ }^{5}$

\section{Hypothesis Testing}

Table 1 presents descriptive statistics, reliability, and correlations between all the study variables.

Hypothesis 1a, that deceptive IM would be negatively related to perceived person-job fit, was supported. Specifically, deceptive IM and person-job fit had a moderate negative relationship, $r=-.19,95 \%$ CI $[-.32,-.06], p=.006$. Hypothesis $1 b$, that deceptive IM would be negatively related to perceived person-organization fit, was also supported. Specifically, deceptive IM and person-organization fit had a moderate negative relationship, $r=-.18,95 \% \mathrm{CI}[-.31,-.05]$, $p=.009$.

Hypothesis 2a, that person-job fit would be negatively related to job stress, was supported, $r=-.43,95 \%$ CI [-.53, $-.31], p<.001$. Hypothesis $2 \mathrm{~b}$, that PJ fit would be positively related to affective well-being, was supported; $r=.73$, $95 \%$ CI $[.66, .79], p<.001$. Hypothesis 2 c, that PJ fit would be positively related to employee engagement, was also supported, $r=.62,95 \%$ CI $[.53, .70], p<.001$.

Hypothesis $3 \mathrm{a}$, that person-organization fit would be negatively related to job stress, was supported, $r=-.51$, $95 \%$ CI $[-.60,-.40], p<.001$. Hypothesis $2 \mathrm{~b}$, that PO fit would be positively related to affective well-being, was supported; $r=.66,95 \%$ CI [.58, .73], $p<.001$. Hypothesis $2 \mathrm{c}$, that $\mathrm{PO}$ fit would be positively related to employee engagement, was also supported, $r=.40,95 \%$ CI $[.28, .51], p$ $<.001$.

\section{Person-Job Fit Model}

For Hypothesis 4, we expected that person-job fit would explain the relations between deceptive IM and job stress (Hypothesis 4a), deceptive IM and well-being (Hypothesis $4 \mathrm{~b}$ ), and deceptive IM and employee engagement (Hypothesis 4c). We assessed these hypotheses by testing the structural model for the manifest variables outlined in Figure 1, with the lavaan package in $\mathrm{R}$ (Rosseel, 2012). The model demonstrated a high level of fit with the data, $\chi^{2}(3)=$ $1.54, p=.67 ; \mathrm{CFI}_{\text {Robust }}=1.00 ; \mathrm{RMSEA}_{\text {Robust }}=0.00,90 \% \mathrm{CI}$ $[0.00, .09]$; SRMR $=.02$. Due to the fit demonstrated by the model, this model was used to examine Hypothesis 4. All path analyses were conducted in lavaan using bootstrapping with 1,000 iterations. Standardized and unstandardized effects are listed in Table 2.

To test Hypothesis 4a, we examined the statistical sig-

5 Participants who completed both surveys $(M=2.48, S D=0.54)$ reported using similar amounts of deceptive IM as participants who only completed the first survey $(M=2.63, S D=0.48), t(267)=-1.87$, $\mathrm{p}=.06$. 


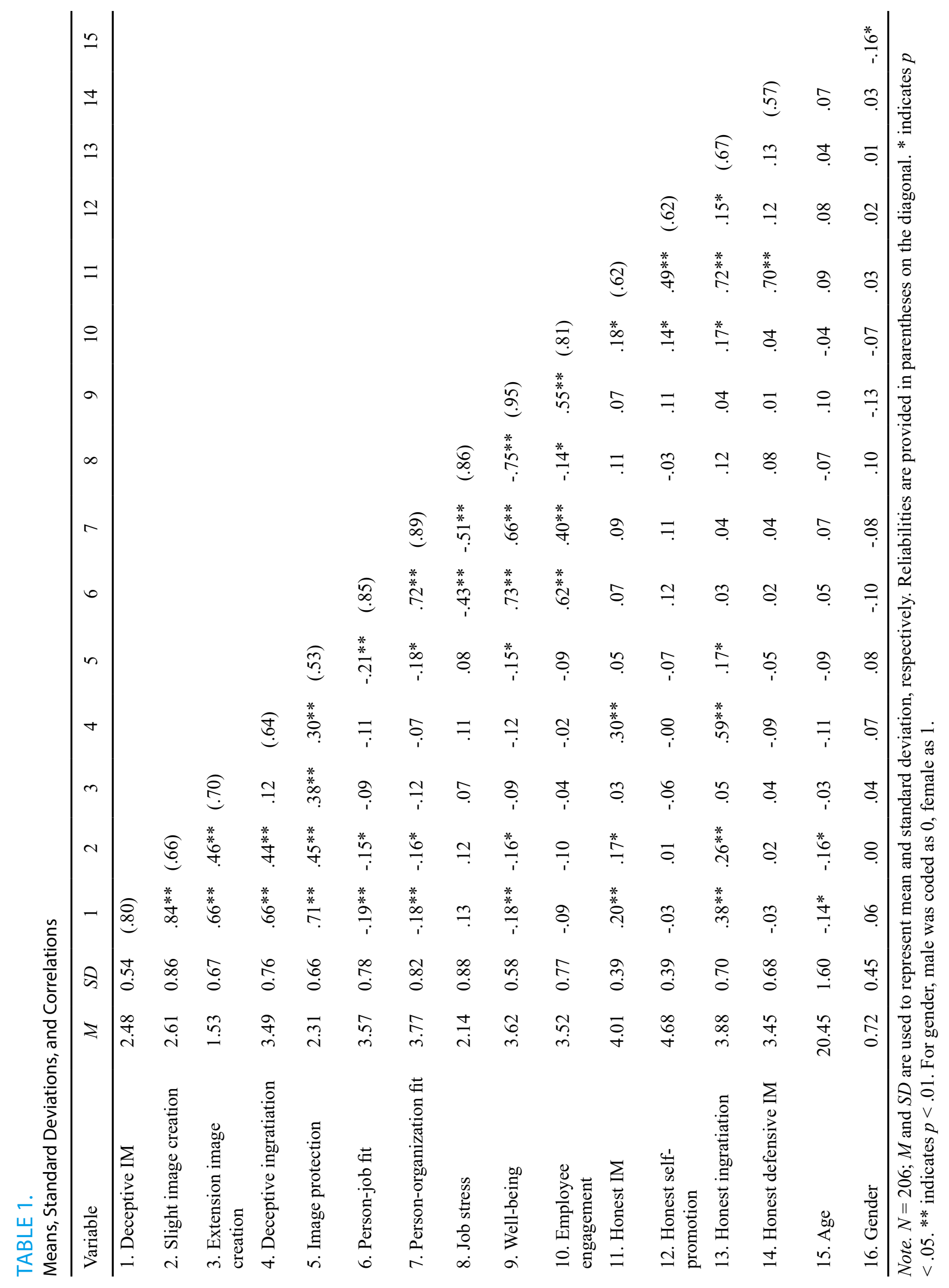


nificance of the indirect path from deceptive IM to personjob fit to job stress. We found support for this hypothesis as the indirect effect between deceptive IM and job stress was positive and significant (standardized effect $=.08,95 \%$ CI $[.02, .14], p=.008)$. However, the size of the effect was small.

For Hypothesis $4 \mathrm{~b}$, we predicted that deceptive IM would be negatively related to well-being, and that this relationship would be explained by person-job fit. We found support for Hypothesis $4 \mathrm{~b}$ as the indirect effect from deceptive IM to fit to well-being in the model was a statistically significant negative relationship (standardized effect $=-.14$, $95 \%$ CI $[-.24,-.04], p=.004)$; however, this was a small effect.

For Hypothesis 4c we expected that deceptive IM would be negatively related to employee engagement, and that this relationship would be explained by person-job fit. We found support for this hypothesis as the indirect effect from deceptive IM through fit to employee engagement was statistically significant (standardized effect $=-.12,95 \% \mathrm{CI}$ $[-.20,-.04], p=.005)$. The effect here was also small.

\section{Person-Organization Fit Model}

For Hypotheses 5, we expected that person-organization fit would explain the relations between deceptive IM and job stress (Hypothesis 5a), deceptive IM and well-being (Hypothesis 5b), and deceptive IM and employee engagement (Hypothesis 5c). We assessed these hypotheses by testing the structural model for the manifest variables outlined in Figure 2, with the lavaan package in R (Rosseel, 2012). The model demonstrated a high level of fit with the data, $\chi^{2}(3)=1.75, p=.63 ; \mathrm{CFI}_{\text {Robust }}=1.00 ; \mathrm{RMSEA}_{\text {Robust }}$ $=0.00,90 \%$ CI $[0.00, .10]$; SRMR $=.02$. Due to the fit demonstrated by the model, this model was used to examine Hypothesis 5. All path analyses were conducted in lavaan using bootstrapping with 1,000 iterations. Standardized and unstandardized effects are listed in Table 3.

To test Hypothesis 5a, we examined the statistical significance of the indirect path from deceptive IM to personorganization fit to job stress. We found support for this hypothesis as the indirect effect between deceptive IM and job stress was positive and significant (standardized effect $=.09,95 \%$ CI $[.01, .17], p=.02)$. However, the size of the effect was small.

For Hypothesis $5 \mathrm{~b}$, we predicted that deceptive IM would be negatively related to well-being, and that this relationship would be explained by person-organization fit. We found support for Hypothesis $4 \mathrm{~b}$ as the indirect effect from deceptive IM to fit to well-being in the model was a small but statistically significant negative relationship (standardized effect $=-.12,95 \%$ CI [-.22, -.02$], p=.02$ ).

For Hypothesis 5c, we expected that deceptive IM would be negatively related to employee engagement, and that this relationship would be explained by person-organization fit. We found support for this hypothesis as the indirect effect from deceptive IM through fit to employee engagement was also small but statistically significant (standardized effect $=-.07,95 \% \mathrm{CI}[-.14,-.01], p=.02$ ).

\section{Exploratory Analyses}

Though we did not have hypotheses for the honest IM, we re-ran our analyses with honest IM in place of deceptive IM to examine the relationship between honest IM, personjob fit, person-organization fit, and our well-being variables. We found that honest IM had a small nonsignificant relationship with person-job fit, $r=.07,95 \%$ CI [-.06, .21], $p=.29$, and person-organization fit, $r=.09,95 \%$ CI [-.05, $.22], p=.20$.

To examine whether person-job fit would explain the relationships between honest IM and job stress, affective well-being, and employee engagement, we tested the structural model for the manifest variables outlined in Figure 3, with the lavaan package in $\mathrm{R}$ (Rosseel, 2012). The model demonstrated an acceptable level of fit with the data, $\chi^{2}(3)=$ $13.72, p=.003 ; \mathrm{CFI}_{\text {Robust }}=0.98 ; \mathrm{RMSEA}_{\text {Robust }}=0.130,90 \%$ CI $[0.07, .21]$; SRMR $=.05$. All path analyses were conducted in lavaan using bootstrapping with 1000 iterations. Standardized and unstandardized effects are listed in Table 4.

We examined the statistical significance of the indirect path from honest IM to person-job fit to job stress and found a small nonsignificant negative effect (standardized effect $=-.03,95 \%$ CI $[-.09, .03], p=.31$ ). For the indirect path from honest IM to person-job fit to affective well-being, we found a small nonsignificant positive relationship (standardized effect $=.05,95 \%$ CI $[-.05, .16], p=.31$ ). For the indirect path from honest to person-job fit to employee engagement, we also found a small nonsignificant positive relationship (standardized effect $=.05,95 \%$ CI $[-.04, .13], p$ $=.31$ ).

To examine whether person-organization fit would account for the relationships between honest IM and job stress, affective well-being, and employee engagement, we tested the structural model for the manifest variables outlined in Figure 4, with the lavaan package in R (Rosseel, 2012). The model demonstrated an acceptable level of fit with the data, $\chi^{2}(3)=13.38, p=.004 ; \mathrm{CFI}_{\text {Robust }}=0.98$; RMSEA $_{\text {Robust }}=0.130,90 \%$ CI $[0.07, .20] ;$ SRMR $=.05$. All path analyses were conducted in lavaan using bootstrapping with 1000 iterations. Standardized and unstandardized effects are listed in Table 5.

We examined the statistical significance of the indirect path from honest IM to person-organization fit to job stress and found a small nonsignificant negative effect (standardized effect $=-.05,95 \%$ CI $[-.11, .02], p=.19$ ). For the indirect path from honest to person-organization fit to affective well-being, we found a small nonsignificant positive relationship (standardized effect $=.06,95 \% \mathrm{CI}[-.03, .15], p$ $=.19$ ). Finally, we examined the indirect path from honest IM to person-organization fit to employee engagement and found a small nonsignificant negative effect (standardized effect $=.04,95 \%$ CI $[-.02, .09], p=.21)$. 
TABLE 2.

Path Coefficients for Person-Job Fit Model

\begin{tabular}{lcccccc}
\hline & $\begin{array}{c}\text { Standardized } \\
\text { path coefficient }\end{array}$ & CI-lower & CI-upper & $\begin{array}{c}\text { Standard } \\
\text { error }\end{array}$ & $\begin{array}{c}\text { P-value } \\
\text { path coefficient }\end{array}$ & $\begin{array}{c}\text { Unstandardized } \\
\text { con }\end{array}$ \\
\hline Deceptive IM $\rightarrow$ PJ Fit & -.19 & -.32 & -.06 & .07 & .004 & -.28 \\
PJ Fit $\rightarrow$ Stress & -.43 & -.56 & -.29 & .07 & $<.001$ & -.48 \\
PJ Fit $\rightarrow$ Well-Being & .73 & .65 & .82 & .04 & $<.001$ & .55 \\
PJ Fit $\rightarrow$ Engagement & .62 & .54 & .70 & .04 & $<.001$ & .00 \\
Indirect: Deceptive IM $\rightarrow$ Stress & .08 & .02 & .14 & .03 & .008 & .00 \\
Indirect: Deceptive IM $\rightarrow$ Well-Being & -.14 & -.24 & -.04 & .05 & .004 & -.15 \\
Indirect: Deceptive IM $\rightarrow$ Engagement & -.12 & -.20 & -.04 & .04 & .005 & -.17 \\
\hline
\end{tabular}

Note. $N=206 ; \mathrm{CI}=95 \%$ confidence interval.

TABLE 3.

Path Coefficients for Person-Organization Fit Model

\begin{tabular}{|c|c|c|c|c|c|c|}
\hline & $\begin{array}{c}\text { Standardized } \\
\text { path coefficient }\end{array}$ & CI-lower & CI-upper & Standard error & P-value & $\begin{array}{l}\text { Unstandardized } \\
\text { path coefficient }\end{array}$ \\
\hline Deceptive IM $\rightarrow$ PO Fit & -.18 & -.33 & -.04 & .07 & .014 & -.28 \\
\hline PO Fit $\rightarrow$ Stress & -.51 & -.64 & -.38 & .07 & $<.001$ & -.55 \\
\hline PO Fit $\rightarrow$ Well-Being & .67 & .55 & .77 & .06 & $<.001$ & .47 \\
\hline PO Fit $\rightarrow$ Engagement & .40 & .27 & .53 & .07 & $<.001$ & .38 \\
\hline Indirect: Deceptive IM $\rightarrow$ Stress & .09 & .01 & .17 & .04 & .02 & .15 \\
\hline Indirect: Deceptive IM $\rightarrow$ Well-Being & -.12 & -.22 & -.02 & .05 & .02 & -.13 \\
\hline Indirect: Deceptive IM $\rightarrow$ Engagement & -.07 & -.14 & -.01 & .03 & .02 & -.11 \\
\hline
\end{tabular}

Note. $N=206 ; \mathrm{CI}=95 \%$ confidence interval.

TABLE 4.

Path Coefficients for Exploratory Honest IM-Person-Job Fit Model

\begin{tabular}{|c|c|c|c|c|c|c|}
\hline & $\begin{array}{c}\text { Standardized } \\
\text { path coefficient }\end{array}$ & CI-lower & CI-upper & Standard error & P-value & $\begin{array}{l}\text { Unstandardized } \\
\text { path coefficient }\end{array}$ \\
\hline Honest IM $\rightarrow$ PJ Fit & .07 & -.07 & .21 & .07 & .31 & .15 \\
\hline PJ Fit $\rightarrow$ Stress & -.43 & -.56 & -.29 & .07 & $<.001$ & -.48 \\
\hline PJ Fit $\rightarrow$ Well-Being & .73 & .65 & .82 & .04 & $<.001$ & .55 \\
\hline PJ Fit $\rightarrow$ Engagement & .62 & .54 & .70 & .04 & $<.001$ & .61 \\
\hline Indirect: Honest IM $\rightarrow$ Stress & -.03 & -.09 & .03 & .03 & .31 & -.07 \\
\hline Indirect: Honest IM $\rightarrow$ Well-Being & .05 & -.05 & .16 & .05 & .31 & .08 \\
\hline Indirect: Honest IM $\rightarrow$ Engagement & .05 & -.04 & .13 & .05 & .31 & .09 \\
\hline
\end{tabular}

Note. $N=206 ; \mathrm{CI}=95 \%$ confidence interval.

TABLE 5.

Path Coefficients for Exploratory Honest IM-Person-Organization Fit Model

\begin{tabular}{|c|c|c|c|c|c|c|}
\hline & $\begin{array}{c}\text { Standardized } \\
\text { path coefficient }\end{array}$ & CI-lower & CI-upper & Standard error & P-value & $\begin{array}{l}\text { Unstandardized } \\
\text { path coefficient }\end{array}$ \\
\hline Honest IM $\rightarrow$ PO Fit & .09 & -.04 & .22 & .07 & .19 & .19 \\
\hline PO Fit $\rightarrow$ Stress & -.51 & -.64 & -.38 & .07 & $<.001$ & -.55 \\
\hline PO Fit $\rightarrow$ Well-Being & .67 & .55 & .78 & .06 & $<.001$ & .47 \\
\hline PO Fit $\rightarrow$ Engagement & .40 & .27 & .53 & .07 & $<.001$ & .38 \\
\hline Indirect: Honest IM $\rightarrow$ Stress & -.05 & -.11 & .02 & .04 & .19 & -.10 \\
\hline Indirect: Honest IM $\rightarrow$ Well-Being & .06 & -.03 & .15 & .05 & .19 & .09 \\
\hline Indirect: Honest IM $\rightarrow$ Engagement & .04 & -.02 & .09 & .03 & .21 & .07 \\
\hline
\end{tabular}

Note. $N=206 ; \mathrm{CI}=95 \%$ confidence interval. 


\section{FIGURE 2.}

Model testing the role of perceived person-organization fit on the relationship between deceptive IM and affective outcomes

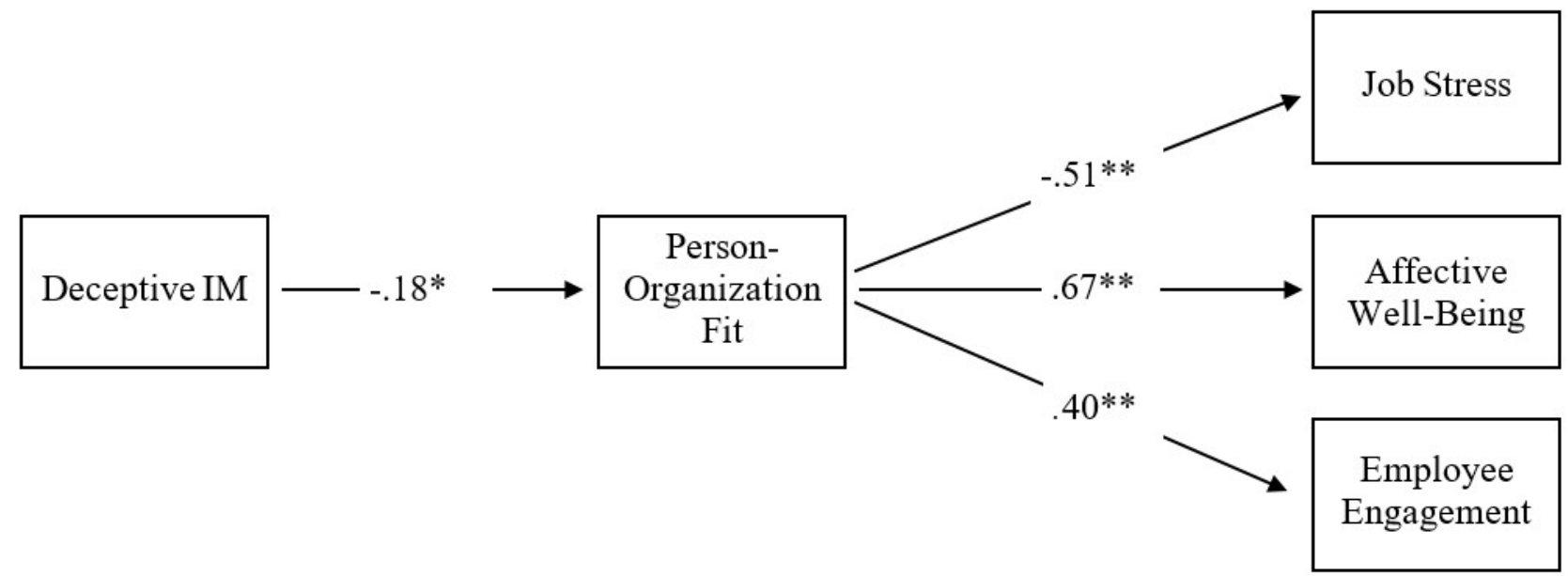

Note. Indirect effect between deceptive IM and job stress was $.09^{*}$, between deceptive IM and affective well-being was $-.12^{*}$, and between deceptive IM and employee engagement was $-.07^{*} . * p<.05,{ }^{* *} p<.01$.

\section{FIGURE 3.}

Mediation model testing the role of perceived person-job fit on the relationship between honest IM and affective outcomes

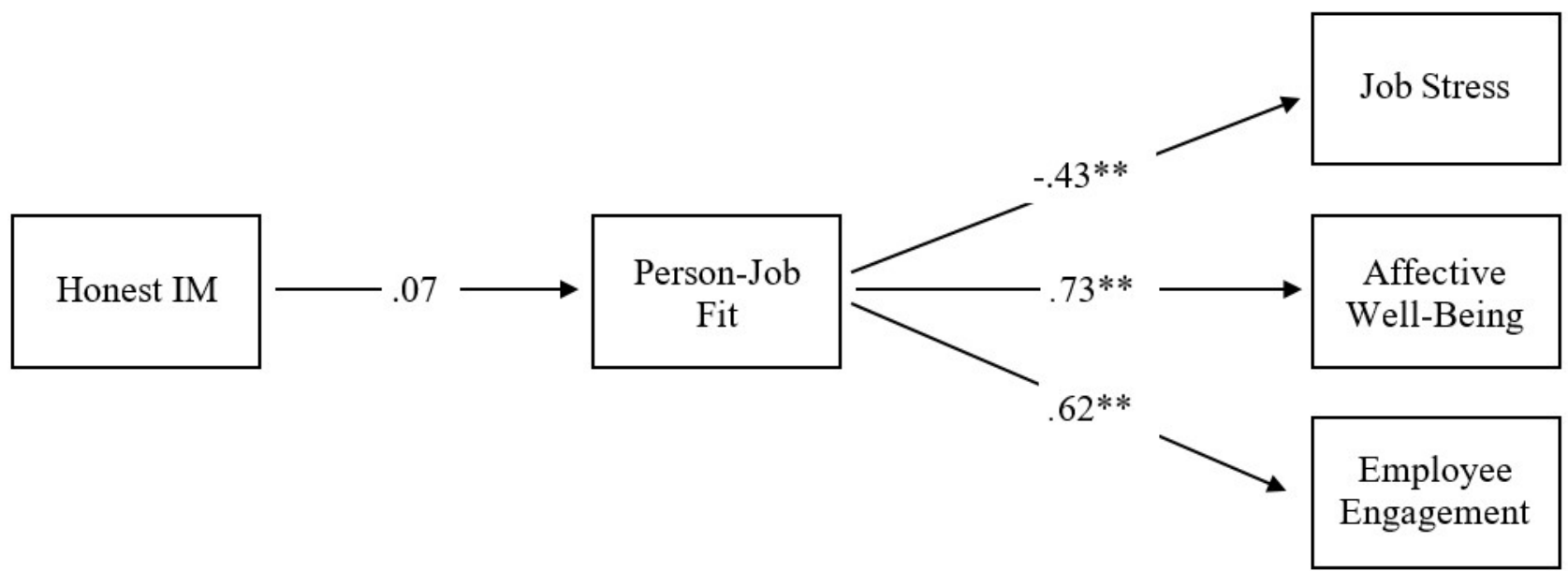

Note. Indirect effect between honest IM and job stress was -.03 , between honest IM and affective well-being was .05, and between honest IM and employee engagement was $.05 .{ }^{*} p<.05,{ }^{* *} p<.01$.

\section{DISCUSSION}

The goal of this research was to investigate the on-thejob costs for new employees who used deceptive IM in their interviews. Specifically, we sought to determine whether employees who used deceptive IM in their interviews experience poor fit with their jobs or organizations, leading to higher stress and lower well-being at work. Deceptive IM use was negatively related to both person-job and personorganization fit ( $r=-.19$ and -.18 , respectively) and also to affective well-being $(r=-.18)$. These effects are small, but taken together, these findings seem to indicate that using deceptive IM in the interview appears to come at a cost to employees.

The three analyses of the indirect effects were found to be statistically significant. Thus, the relationship between deceptive IM and the outcome variables of job stress, affective well-being, and employee engagement appear to work, in part, through lack of fit. However, because perceived fit and the dependent variables of stress, well-bring, and en- 


\section{FIGURE 4.}

Mediation model testing the role of perceived person-organization fit on the relationship between honest IM and affective outcomes

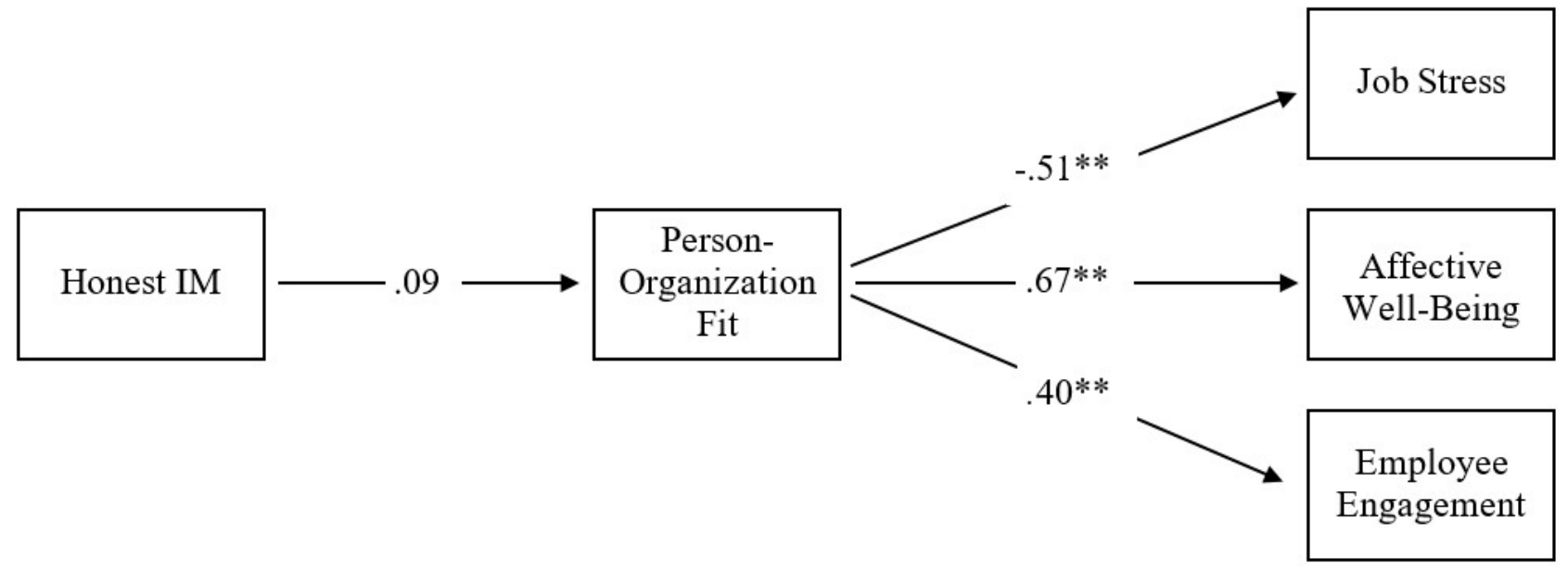

Note. Indirect effect between honest IM and job stress was -.05 , between honest IM and affective well-being was .06, and between honest IM and employee engagement was $.04 . * p<.05, * * p<.01$.

gagement were all self-reported and measured at the same time, there is some risk of common-method variance, which could also partly explain the strong relationships between perceived fit and the dependent variables.

When looking at the correlations in Table 1, it appears that the direct relationships between deceptive IM and workplace outcomes are strongest for perceived fit and affective well-being (and less so for job stress and employee engagement). In terms of the deceptive IM subscales, the relations with workplace outcomes were strongest for slight image creation and image protection. Overall, it appears that there may be a cost, particularly in terms of fit and affective well-being, for applicants who use slight image creation and image protection as techniques during their interview.

Although we did not have any specific hypotheses about honest IM use, we did explore a parallel set of analyses with the honest IM scale. Interestingly, the effects with honest IM were in the opposite direction of the deceptive IM findings, but they were also smaller and nonsignificant. These findings provide further evidence that separating out deceptive and honest IM in research is important, as the consequences of each form of IM appear to be quite different.

There are a few limitations with this study, in particular in terms of the sample used. A unique feature of the job applicants in this sample is that participants did not fill out the survey until they had obtained a job. Therefore, the findings may not be representative of job applicants who do not obtain jobs. Additionally, our sample was composed of co-op students who were on short 4-month work terms. This could cause some peculiarities with the sample, as co-op students could feel differently or behave in different ways than the general working population. In addition, co-op students only spend 4 months on each work term and may not be seriously affected if they do not enjoy their jobs. Because students know that their jobs will soon end, they might be less concerned about work than typical employees. In order to further the generalizability of future studies, researchers should consider obtaining different types of samples in addition to co-op students.

However, our research question related to job outcomes for new employees who obtained a job following an interview, which was well-suited to the co-op student sample. As well, because co-op positions are, for many students, their first professional career opportunities and many of the students seek to gain re-employment for subsequent co-op terms and for post-education employment, these positions are important to students and students' success on these jobs is consequential at this formative stage of their careers. Thus, co-op students were chosen as a sample despite these limitations.

One of the main strengths of this study lay in the twophase study design used to answer the research questions. In order to avoid issues inherent with having participants answer a survey on interview behavior and job behavior at one time point, this study utilized a two-phase study design where participants were sent one survey asking about their interview and another survey sent months later asking about their job behaviors. This is a major strength of this study, as it meant that there was a shorter period of time between participants' interviews and their interview survey than 
if we sent both surveys after they had been working for 2 months. Additionally, as participants had not yet begun working when they answered the Time 1 survey, their interview data could not be impacted by their job experiences. This two-phase design also improved the analysis of indirect effects. Because deceptive IM was measured months before the other variables, it could not have been caused by participants' perceived fit, job stress, affective well-being, or employee engagement. This helps to provide support for the indirect effects, because deceptive IM could impact the other variables, but the other variables could not impact deceptive IM.

An additional strength is that the study was based on actual job interviews and actual job data for co-op students. Many studies examining interview behaviors use mock interviews; however, it can be difficult to generalize behaviour from mock interviews to real life interviews. In this study, participants went through their interviews knowing that they had to obtain a co-op job in order to stay in their co-op program. This would have added pressure to their interviews, because participants knew that their interview performance could lead to them getting a job.

This study investigated a novel question of the potential costs of deceptive IM in terms of person-job and person-organization fit and mental well-being, and we found that deceptive IM has negative effects on new employees. Although a main goal of the employment interview is to maximize the "fit" between the candidate and the job, it appears that the use of deceptive IM may interfere with this information exchange; whereas deceptive IM could improve the chances of a candidate getting a job, the longer term effects for employees are harmful. To improve the honesty of the information exchange, applicants could still engage in IM, but use honest tactics, such as honestly promoting their skills and abilities. Indeed, honest IM appears to be more beneficial than deceptive IM in terms of improving interview scores (Ho et al., in press). From the employer point of view, literature (e.g., Levashina et al., 2014) has suggested that using elements of structure in the employment interview, such as limiting rapport building and using structured rating scales to assess responses, may reduce opportunities for applicants to engage in IM. Interestingly, Wilhelmy et al. (2020) found, in an analysis of the text of interviews, that applicants actually adapt their pattern of IM to the interviewer's use of IM. Thus, it may be possible for the interviewer to set the tone for the interview by, for example, providing accurate and honest information about the job position and the organization. An open and honest exchange of signals will be beneficial to both the organization and its future employees.

\section{REFERENCES}

Bangerter, A., Roulin, N., \& König, C. J. (2012). Personnel selection as a signaling game. Journal of Applied Psychology, 97(4), 719-738. doi:10.1037/a0026078

Bourdage, J. S., Roulin, N., \& Tarraf, R. (2018). “I (might be) just that good": Honest and deceptive impression management in employment interviews. Personnel Psychology, 71(4), 597-632. doi:10.1111/peps.12285

Connelly, B., Certo, S., Ireland, R., \& Reutzel, C. (2011). Signaling theory: A review and assessment. Journal of Management, 37(1), 39-67. doi:10.1177/0149206310388419

Edwards, J.R., \& Shipp. A.J. (2007). The relationship between person-environment fit and outcomes: An integrative theoretical framework. In C. Ostroff \& T.A. Judge (Eds.), Perspectives on organizational fit (pp. 209-258). San Francisco, CA: Jossey-Bass.

Ho, J. L., Powell, D. M., \& Stanley, D. J. (in press). The relation between deceptive impression management and employment interview ratings: A meta-analysis. Canadian Journal of Behavioural Science.

Kristof-Brown, A., Barrick, M., \& Franke, M. (2002). Applicant impression management: Dispositional influences and consequences for recruiter perceptions of fit and similarity. Journal of Management, 28(1), 27-46. doi:10.1177/014920630202800103

Lambert, E., Hogan, N., Camp, S., \& Ventura, L. (2006). The impact of work-family conflict on correctional staff. Criminology \& Criminal Justice, 6(4), 371-387. doi:10.1177/1748895806068572

Levashina, J., \& Campion, M. A. (2006). A model of faking likelihood in the employment interview. International Journal of Selection and Assessment, 14(4), 299-316. https://doi. org/10.1111/j.1468-2389.2006.00353.x

Levashina, J., \& Campion, M. A. (2007). Measuring faking in the employment interview: Development and validation of an interview faking behavior scale. Journal of Applied Psychology, 92, 1638-1656. doi: 10.1037/0021-9010.92.6.1638

Levashina, H., Hartwell, C. J., Morgeson, F. P., \& Campion, M. A. (2014). The structured employment interview: Narrative and quantitative review of the research literature. Personnel Psychology, 67(1), 241-293. https://doi.org/10.1111/ peps. 12052

Marcus, B. (2009). "Faking" from the applicant's perspective: A theory of self-presentation in personnel selection settings. International Journal of Selection and Assessment, 17(4), 417-430. https://doi.org/10.1111/j.1468-2389.2009.00483.x

McFarland, L. A., \& Ryan, A. M. (2006). Toward an integrated model of applicant faking behavior. Journal of Applied Social Psychology, 36(4), 979-1016. https://doi.org/10.1111/ j.0021-9029.2006.00052.x

Melchers, K. G., Roulin, N., \& Buehl, A. K. (2020). A review of applicant faking in selection interviews. International Journal of Selection and Assessment, 28(2), 123-142.

Rosseel, Y. (2012). lavaan: An R package for structural equation modeling. Journal of Statistical Software, 48(2), 1-36.

Rounds, J. B., \& Tracey, T. J. (1990). From trait-and-factor to person-environment fit counseling: Theory and process. In W. B. Walsh \& S. H. Osipow (Eds.), Career counseling: Contem- 
porary topics in vocational psychology (pp. 1-44). Lawrence Erlbaum Associates, Inc.

Saks, A. M. (2006). Antecedents and consequences of employee engagement. Journal of Managerial Psychology, 21(7), 600. doi: 10.1108/02683940610690169

Saks, A. M., \& Ashforth, B. E. (1997). A longitudinal investigation of the relationships between job information sources, applicant perceptions of fit, and work outcomes. Personnel Psychology, 50(2), 395-426. doi:10.1111/j.1744-6570.1997. tb00913.x

Spence, M. (1973). Job market signalling. Quarterly Journal of Economics, 87(3), 355-374. doi: 10.2307/1882010

Van Katwyk, P. T., Fox, S., Spector, P. E., \& Kelloway, E. K. (2000). Using the Job-Related Affective Well-Being Scale (JAWS) to investigate affective responses to work stressors. Journal of Occupational Health Psychology, 5(2), 219-230. doi:10.1037/1076-8998.5.2.219

Wilhelmy, A., Roulin, N. \& Wingate, T.G. (2020). Does it take two to tango? Examining how applicants and interviewers adapt their impression management to each other. Journal of Business Psychology. https://doi.org/10.1007/s10869020-09720-5

RECEIVED 09/09/20 ACCEPTED 01/14/21 